\title{
The research on the fairness of carbon emissions for China's energy based on GIS
}

\author{
Qiuxian Wang *a,b,d , Zhiqiang Gao ${ }^{\text {a,c }}$, Jicai Ning ${ }^{\text {a }}$, Qing-shui Lu ${ }^{\text {a }}$, Runhe Shi ${ }^{\mathrm{c}}$,Wei Gao ${ }^{\mathrm{c}}$ \\ ${ }^{a}$ Yantai Institute of Coastal Zone Research, \\ Chinese Academy of Sciences, Yantai, 264003 China; \\ ${ }^{\mathrm{b}}$ University of Chinese Academy of Sciences, Beijing,100049 China; \\ ${ }^{\mathrm{c}}$ USDA UV-B Monitoring and Research Program, Natural Resource Ecology Laboratory, Colorado \\ State University, Fort Collins, CO, USA; \\ d. Institute of geography and planning, Ludong University, Yantai 264025, China
}

\begin{abstract}
This article firstly calculated China's energy carbon emissions of 30 provinces in 2010 with the method of carbon emission inventories of 2006 IPCC based on the data of China energy statistical yearbook, and then calculated its carbon emission intensity with GDP data in China's statistical yearbook. Next according to the formed formula the author calculated the EEI (Economic Efficiency Index) and ECI (Ecological Carrying Index) and made some corresponding figures with the help of GIS to analyze the fairness of the China's energy $\mathrm{CO}_{2}$ emissions in 2010. The results showed that the distribution of China's $\mathrm{CO}_{2}$ emissions for energy in 2010 become lower from the Bohai bay to the surroundings and the west circle provinces are with the lowest energy carbon emissions. The intensity distribution of China's $\mathrm{CO}_{2}$ emissions for energy in 2010 becomes higher from southeast China to north China. The distributions of EEI, ECI and for China's energy $\mathrm{CO}_{2}$ emissions are quite different from each other, and also with their comprehensive result. As to the fairness of China's energy $\mathrm{CO}_{2}$ emissions in 2010, we can say that the south provinces are better than those of Bohai bay areas(except Beijing and Tianjing).
\end{abstract}

Key words: fairness, carbon emission, China's energy, GIS, EEI , ECI

\section{INTRODUCTION}

Since the rapid economical development depends much on energy in today's China, it has been the largest country in greenhouse gas emissions occupying $10 \%$ of the whole World's amount ${ }^{[1]}$. As a responsible country, China officially pledged to reduce its $\mathrm{CO}_{2}$ emissions per GDP (or $\mathrm{CO}_{2}$ intensity) by $40-45 \%$ from the level of 2005 and increase the share of non-fossil energy in primary energy to $15 \%$ by 2020 in November $2009^{[2]}$. To reach the goal, China will assign carbon emission reduction task to each provincial administrative areas. So it is very important for us to study the fairless of the carbon emissions for Chinese energy in provinces' level. As to enhance the fairness of this work, the author constructed the carbon emissions equity evaluation model which includes economic and ecological contribution index for energy carbon emission according to Lu Junyu ${ }^{[3]}$. Then with the contribution index matrix, the author classified the provinces

Address correspondence to * qiuxianpw@163.com

Remote Sensing and Modeling of Ecosystems for Sustainability X, edited by Wei Gao, Thomas J. Jackson, Proc. of SPIE Vol. 8869, 886910 - () 2013 SPIE

CCC code: $0277-786 X / 13 / \$ 18 \cdot$ doi: $10.1117 / 12.2022413$

Proc. of SPIE Vol. $8869886910-1$ 
into four kinds. As an important tool for the spacial study, GIS was often used to show spacial distribution dirrectly and clearly. In this article the author also analyzed the four kinds of carbon emission with GIS, in order to provide the basis references for the differentiated regional emission reduction policies and emission reduction targets of the state formulates.

\section{METHODOLOGY}

\subsection{Data Description}

The fossil fuels data used in this paper are from fossil fuels China energy statistical yearbook ${ }^{[4]}$, Chinese GDP and other social and economic data are from China statistical yearbook ${ }^{[5]}$, the carbon emissions parameters of energy are from listing of IPCC $2006^{[6]}$. As for the land use data used in the calculation of ECI, the paper chose the NDVI data of 2010 from SPOT NDVI data with 36 VGT-S10 files. Then with the DEM data from SRTM3 (Shuttle Radar Mission) assisting Topography, whose spatial resolution is $90 \mathrm{~m} * 90 \mathrm{~m}$, the paper processed after land cover classification.

\subsection{The calculation methods of China's $\mathrm{CO}_{2}$ emissions for fossil fuels}

According to the fourth assessment report of IPCC in 2007, the main source of increased greenhouse gases is the burning of fossil fuels (carbon dioxide emissions in the burning of fossil fuels is near $95.13 \%$ of the world total emissions in 2004) ${ }^{[7]}$. And in the world wide the emissions inventory method of IPCC 2006 is often used, so in this article we calculate China's energy carbon emissions in 30 provinces(excluding Xizang municipality for its lost of related data)with it. In order to avoid the larger error made by the direct use of primary energy, the data this article used is from the energy statistical yearbook of China statistics of the eight class final energy data, including raw coal, coke, crude oil, gasoline, kerosene, diesel oil, fuel oil and natural gas, with reference to the IPCC guidelines ${ }^{[8]}$ providing various fuel carbon content by default, and various fuel $\mathrm{CO}_{2}$ emission factor per unit of energy of the default; To convert units of various fuel into ordinary energy unit, this article introduced low calorific value used in energy statistics in China ${ }^{[9]}$. The resulting computation formula is as follows: Suggested emission factor

$$
=\text { carbon oxidation factor * original emission factor *calorific value in China }
$$

That is

$$
E F_{i}=O X I D_{i} * E F_{\mathrm{co}_{2}, i} * N C V_{I}
$$

In which ${ }^{N C V_{t}}$ means the net calorific value unit mass or volume of the fuel i (energy content), and is a national designated value. ${ }^{O X I D_{i}}$ is the oxidation rate for fuel $\mathrm{i}$, and is the IPCC default value. ${ }^{E F_{\mathrm{co}_{2}, i}, \mathrm{is}}$ the default $\mathrm{CO}_{2}$ emission factor for fuel $\mathrm{i}$ of per unit energy, and is also the IPCC default value which equals to default carbon content of fuel $\mathrm{i}$ $* 44 / 12$.

On the basis of $\mathrm{CO}_{2}$ emission coefficient for a variety of fossil fuels, emission source activity (that is, the fuel consumption) was selected in this paper to calculate the carbon emissions of fossil fuels. The specific calculation formula is as follows:

$$
Y_{e}=E_{\mathrm{ij}} F_{i j y} * E F_{I}
$$

In the figure 2, ${ }^{Y_{e}}$ means the $\mathrm{CO}_{2}$ emissions for fuels. $F_{i j}$ is the activity intensity, which means the consumption of the fuel $\mathrm{I}$ (which is often calculated by mass or volume ) in the year $\mathrm{Y}$ of the province $\mathrm{J}$. 


\subsection{Economic efficiency index (EEI)}

From the point of economy, if the proportion of carbon emissions in one province is greater than that of its GDP, it belongs to the relatively low economic efficiency and it encroaches on the interests of other provinces; on contrary, the province is with higher economic efficiency. So in this part, economic efficiency index (EEI) mainly takes the provincial GDP as reference to be calculated, whose formula is as the following:

$\mathrm{EEI}=$ the rate of economic contribution/the ratio of carbon emission

$$
E E I=\frac{G_{i}}{G} / \frac{Y_{i}}{Y}
$$

In which Gi and G are regional and national GDP respectively; Yi and $\mathrm{Y}$ are the carbon emissions of the province and the whole China respectively.

\subsection{Ecological carrying index (ECI)}

From the point of ecology, the carbon sink in one province should be more than its carbon emission, so that its ecological environment can be in good conditions. If the ratio of carbon emissions in one province is greater than that of its carbon sinks, we say that the province makes the other regions bear too much for their carbon emissions impact to the ecological environment. On the contrary, it belongs to the relatively high level of ecological capacity and contributes much to reduce the pressure of carbon emissions to the ecological environment ${ }^{[3]}$. In this view, the author follows its formula and calculates the ESI, the formula is as following:

Ecological carrying index $(\mathrm{ECI})=$ the ratio of its carbon sink / ratio of its carbon emission

$$
E C I=\frac{A_{i}}{A} / \frac{Y_{i}}{Y}
$$

in which $\mathrm{Ai}$ and $\mathrm{A}$ are regional carbon sink and national carbon sink respectively, $\mathrm{Yi}$ and $\mathrm{Y}$ are regional carbon emissions and national carbon emissions respectively. As to the carbon sink, the author selects forest land and grass land as the main carbon sink resources to calculate it according to the current domestic research status. The estimation folume is as following:

$$
A=\sum_{i=1}^{i=n} T_{i} \times s_{i}
$$

in which $\mathrm{A}$ is the total carbon sink of different land use types; Ti is the area of different land use types, which includes forestry land area and grassland area. Si is the carbon sink coefficient for the kind of land use i, which is according to the research result of Fangjingyun etc ${ }^{[10]}$ (the carbon sink coefficient of the forest is $5.77 \mathrm{~kg} / \mathrm{m}^{2} \mathrm{y}$, and the carbon sink coefficient of the grassland is $0.0021 \mathrm{~kg} / \mathrm{m}^{2} \mathrm{y}$ ).

\section{RESULTS ANALYSIS}

\subsection{China's energy carbon emissions and its intensity distribution in $\mathbf{2 0 1 0}$}

According to the formula of carbon emission, the author calculated China's energy carbon emissions in each province firstly and then made a distribution map like figure 1a with ARCGIS 10.0. From the figure we can see that Shandong, Hebei, Jiangsu and Liaoning province are the in the top grade for their carbon emissions. The second carbon emission grade includes Henan, Guangdong and Inner Mongolia three provinces. While the provinces with low carbon emission are mainly distributes in the west China, like Qinghai, Gansu, Ningxia, Chongqing and others. It is worth referring that Beijing, Shanghai and Tianjin are with low carbon emission. 


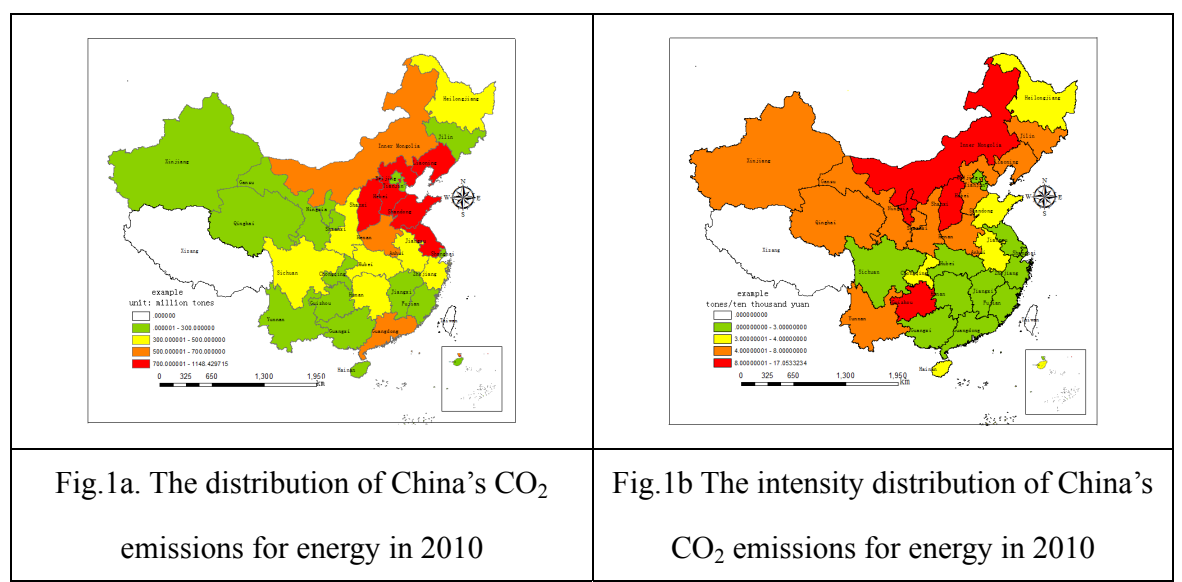

Next with GDP data from China's statistical yearbook of 2010, the author calculated the intensity of $\mathrm{China}^{\mathrm{s}} \mathrm{CO}_{2}$ emissions for energy and made figure $1 \mathrm{~b}$ to show their distribution. From the figure we can see that the provinces with high intensity for China's energy carbon emission are mainly in Shanxi, Guizhou, Ningxia and Inner Mongolia, which are among the top four provinces in China. While Fujian, Guangdong, Beijing, Jiangsu, Zhejiang, Shanghai and other provinces are in low carbon emissions intensity, which reflects their low energy consumption characteristics.

\subsection{The analysis on the fairness of EEI for China's energy carbon emissions}

According to formula (3), the author calculated the regional EEI for China's energy carbon emissions based on its GDP and mapped their distribution in 2010 as figure 2a by ways of Arcgis10.0. From figure 2a we see that EEI distribution is very regular in China, which indicates that EEI reduces from southeast China to the northwest China. The area with EEI $>1$ mainly distributed in the southeast coastal provinces and Beijing city. And next is Hebei, Anhui, Jiangsu, Chongqing, Sichuan and Guangxi province. While the area with EEI less than 1 mainly distributed in the north China like Shandong, Shaanxi, Gansu, Qinghai, Liaoning etc. The least EEI for China's energy carbon emissions distributed in Xinjiang, Inner Mongia, Ningxia and Shanxi provinces.

\subsection{The analysis on the fairness of ECI for China's energy carbon emissions}

According to the research methods in 2.4 in this paper, the author firstly attracted the area of forestry land and grass land from the land sat data base in 2010, and then calculated the different ESIs of each province in China to shape

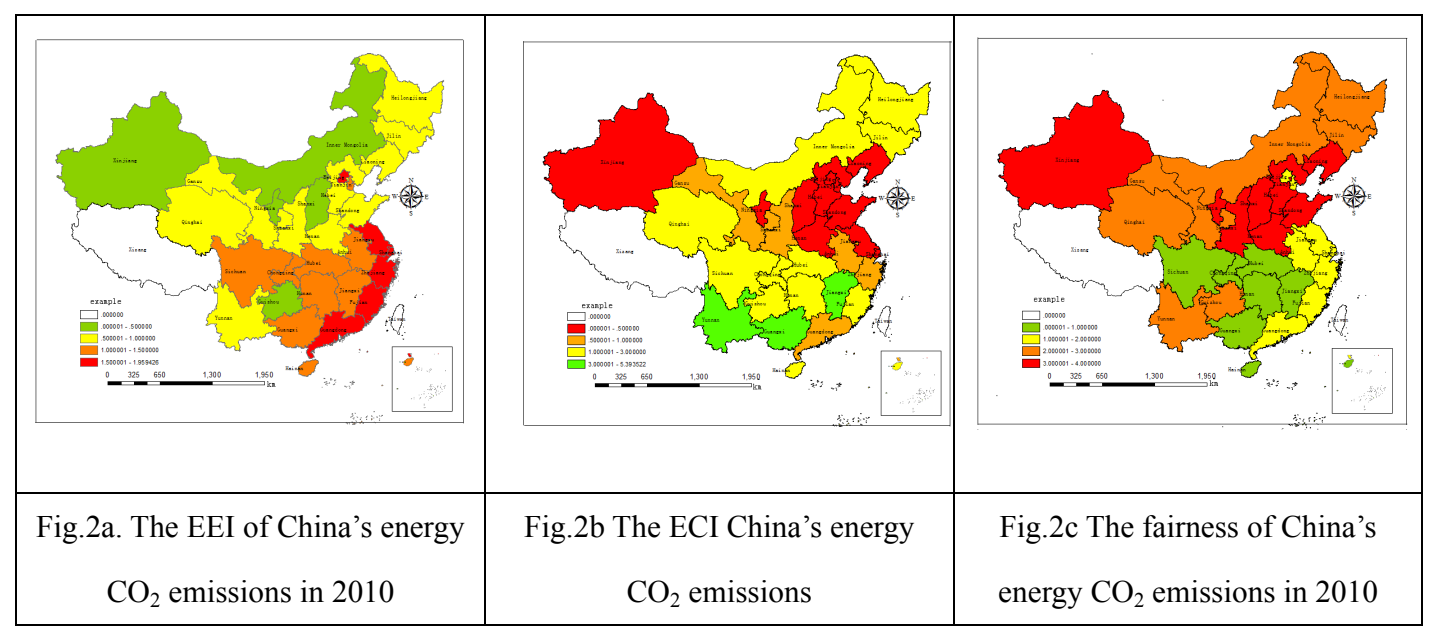

figure2b with Arcgis10.0. From the figure we can see that the ECI changes from east China to West China to south China 
with the regular of changing higher and higher, which means that the ESIs in Liaoning, Hebei, Shandong, Jiangsu, Shaanxi, Henan, Tianjin, Shanghai and Beijing are in minimum value with their ECIs less than 0.5, the next grade is made up of five provinces including Gansu, Shaanxi, Anhui, Zhejiang and Guangdong Province, while the other provinces are in the good ecology conditions with their ECIs more than 1 as seen in the figure $2 \mathrm{~b}$.

\subsection{The analysis fairness of China's energy carbon emissions}

Based on the economic efficient index (EEI) and ecological carrying index(ECI) of carbon emissions for China's energy, this paper divided China's energy fairness into four parts. The standard is that the provinces with both EEI and ECI higher than 1 belong to part 1, the provinces with EEI higher than 1 and ECI lower than 1 belong to part 2, the provinces with EEI lower than 1 and ECI higher than 1 belong to part 3, the provinces with both EEI and ECI lower than 1 belong to part 4. Thus the distribution of the fairness on China's energy carbon emissions has been formed according to the rules, as shown in figure $2 \mathrm{c}$.

It can be seen that Guangxi, Jiangxi, Sichuan, Hunan, Hubei, Hainan and Chongqing are seven provinces distributed in southeast China area, which belong to part 1 with their high economy efficiency and high ecological capacity compatibility. The second part includes Beijing, Tianjin, Shanghai, Guangdong, Zhejiang, Jiangsu, Fujian and Anhui eight provinces, which distributed in the middle and lower reaches of the Yangtze River area in China. These provinces

have high economic efficiency in energy carbon emissions, but at the same time their energy carbon emissions produced a huge pressure on the ecological environment from the point of ecology. The third class area mainly includes Qinghai, Yunnan, Inner Mongolia autonomous region, Heilongjiang province, Gansu province, Guizhou and Jilin province, which mainly distributed in northern and central China with their energy carbon emissions adapting to ecological environment capacity highly but their economic efficient index low. Class 4 areas mainly concentrated in the Bohai rim region, which includes Shandong, Shanxi, Liaoning, Hebei, Henan, Shaanxi, Xinjiang and Ningxiahuizu autonomous region, which show a disadvantage in both economy efficiency and ecological capacity and need to speed up their adjustment of industrial structure and energy consumption structure in order to enhance their regional EEI and their ecological capacity.

\section{DISCUSSION}

\subsection{China's energy carbon emissions have some relations with their economy in 2010}

According to figure 1a, we can see that the top grade of energy carbon emissions are mainly distribute in Bohai bay area, which indicates that their rapid economy development depends much on energy, except Beijing and Tianjin. While the provinces with low carbon emission mainly distributes in the west China, where the economy develops slower than east China.

As to figure $1 \mathrm{~b}$ we could see more clearly that the provinces with high carbon emission intensity like Shanxi are still in the condition that the regional economic development depends much on energy consumption. At the same time many coastal provinces with high economic growth are now in low carbon emissions intensity, like Fujian, Guangdong, Beijing, Jiangsu, Zhejiang, Shanghai and other provinces, which indicates that their energy efficiency are high with their technology progress, energy structure improvement, and their carbon emission reduction are in a good situation.

Proc. of SPIE Vol. $8869886910-5$ 


\subsection{The analysis method of fairness on China's energy carbon emissions}

In this article, the author analyzing the fairness of China's energy carbon emissions mainly used the method of $\mathrm{Lu}$ $\mathrm{Junyu}^{[3]}$, only considering its economy and its ecology capability. But in fact as to the fairness of the regional energy carbon emissions, it can also consider the regional population, regional area and other conditions. And the fairness of regional energy carbon emissions can also be analyzed by a comprehensive index. In later work we can do something to realize it.

\section{CONCLUSION}

From above analysis we can draw the conclusions as the following:

(1) The distribution of China's $\mathrm{CO}_{2}$ emissions for energy in 2010 become lower from the Bohai bay to the surroundings, and the west circle provinces are with the lowest energy carbon emissions.

(2) The intensity distribution of China's $\mathrm{CO}_{2}$ emissions for energy in 2010 becomes higher from southeast China to north China.

(3) The distributions of EEI, ECI and for China's energy $\mathrm{CO}_{2}$ emissions are quite different from each other, and also with their comprehensive result. As to the fairness of China's energy $\mathrm{CO}_{2}$ emissions in 2010, we can say that the south provinces are better than those of Bohai bay area (except Beijing and Tianjin).

\section{ACKNOWLEDGES}

The authors are grateful for the support from Natural Science Foundation of China (41171334, 41071278), Ecological Innovation \& Breeding Project (Y254021031, 355031061) and USDA NIFA project (2010-34263-21075) .

\section{REFERENCE}

[1] The energy and carbon emissions analysis in China's sustainable development group of Energy research institute, "The study on China's energy and carbon emissions scenario, " Journal of research and exploration, (2007).

[2]Hu J, "Presentation at climate change summit meeting in New York, " http://www.mfa.gov.cn/eng/wjdt/zyjh/t616862.htm, Sep. (2009).

[3] Lu Junyu, Huang Xianjin, Daijing etc, "The equity analysis of provincial energy consumption carbon emissions on the time and space scale," Journal of natural resources, 27 (12) : 2006-2017, (2012)

[4] National bureau of statistics (NBS), [China energy statistical yearbook 2011]. China statistical publishing house, (2012).

[5] National bureau of statistics (NBS). [China statistical yearbook 2011]. China statistical publishing house, (2012).

[6] IPCC. [Contribution of Working Group III to the Fourth Assessment Report of the Intergovernmental Panel on Climate Change]. Cambridge: Cambridge University Press, (2007).

[7] Leemans, R.; Eickhout, B.; Strengers, B., "The consequences of uncertainties in land use, climate and vegetation responses on the terrestrial carbon," SCIENCE IN CHINA SERIES C LIFE SCIENCES -ENGLISH EDITION-, ISSN 1006-9305, Volume 45, Issue PART SU, 01, Page Count 16,(2002) 
[8] IPCC, [Summary for Policymakers of Climate Change 2007: The Physical Science Basis]. Cambridge: Cam 2 bridge University Press, (2007).

[9] National bureau of statistics (NBS) GongJiaoSi, [Energy statistics knowledge handbook]. National bureau of statistics. (2010)

[10] Fang jingyun, Guo Zhaodi, PiaoShiLong etc, "The estimation of Chinese terrestrial vegetation carbon sequestration in 1981 2000," Science in China, 5 (6) : 804-812. (2007)

[11]Zeng Xiangang, Pang Hanshuang., "The study on the situation, trend and its reduction countermeasures for China's CO2 emissions in each province, ” Supplement Journal of China soft science (top).6:65. (2010) 